\title{
BUSCANDO ANALOGIAS NO LIVRO DIDÁTICO: USO E ABORDAGEM NA EDUCAÇÃO EM SAÚDE NO ENSINO FUNDAMENTAL EM BOA VISTA-RR
}

\section{SEEKING ANALOGIES IN TEXTBOOKS: USE AND APPROACH ABOUT HEALTH EDUCATION FOR ELEMENTARY SCHOOLS IN BOA VISTA-RR.}

\author{
Ricardo Luiz Ramos ${ }^{1}$, Maria Eloisa Farias ${ }^{2}$, Tania Renata Prochnow ${ }^{3}$ \\ ${ }^{1}$ Mestre pelo Programa de Ensino de Ciências e Educação Matemática - PPGECIM/ULBRA-Canoas - \\ rluizramos@gmail.com \\ ${ }^{2}$ Professor-pesquisador do Programa de Ensino de Ciências e Educação Matemática - \\ PPGECIM/ULBRA-Canoas - mariefs10@yahoo.com.br \\ ${ }^{3}$ Professor-pesquisador do Programa de Ensino de Ciências e Educação Matemática - \\ PPGECIM/ULBRA-Canoas - taniapro@gmail.com
}

\begin{abstract}
RESUMO
As escolas estaduais do ensino fundamental de Boa Vista-RR adotam livros didáticos enviados pelo Ministério da Educação que possuem uniformização dos conteúdos para todo Brasil. Este trabalho apresenta uma pesquisa documental analítica, fundamentada no método dedutivo comparativo e observação da prática docente com cinco professores de ciências, no ano letivo de 2009. Trata-se da análise do uso de analogias nos temas de educação em saúde, no livro didático de sétimo ano do ensino fundamental, utilizado pelas escolas. É um trabalho exploratório, que necessita de maior aprofundamento. A análise evidenciou que o livro selecionado não utiliza analogias na abordagem destes temas, porém na sala de aula a estratégia é muito utilizada pelos professores, sendo uma ferramenta valiosa entre conhecimentos diferentes, um conhecido e outro desconhecido, importante na aprendizagem de conceitos difíceis; também é utilizada sob forma inadvertida de conceitos reducionistas, generalizando seu uso na prática docente, embora ausentes no livro analisado.
\end{abstract}

Palavras-chave: Analogias. Educação em saúde. Livro didático.

\begin{abstract}
State schools of elementary education at Boa Vista-RR adopt textbooks sent by the Ministry of Education that have uniform content throughout Brazil. This paper presents an analytical documentary research, based on the deductive method of comparison, and observation of teaching practice five science teachers, in the 2009 school year. It is the analysis of the use of analogies in topics of health education textbook in seventh year, used in the schools. It is an exploratory work that needs further elaboration. The analysis revealed that the selected book does not use analogies in addressing these issues, but in the classroom strategy is widely used by teachers, being a valuable tool between different knowledge, a well-known and others unknown, important in learning difficult concepts; also is used in the form inadvertently reductionist concepts, generalizing its use in teaching practice, although absent in the book analyzed.
\end{abstract}

Keywords: Analogies. Health education. Textbook. 


\section{Introdução}

Os métodos e estratégias didáticas para o processo de ensino e aprendizagem são diversos e perpassam o comportamentalismo, cognitivismo, humanismo e suas subdivisões. Necessariamente estas formas de sistematizar o ensino passam pelo crivo didático pedagógico docente que dispõe de uma grande variedade de estratégias de ensino, como potencial capaz de produzir conhecimentos.

Reportando-se aos conteúdos do ensino fundamental, além dos conteúdos comuns previstos nas disciplinas, foram incluídos os temas transversais determinados nos PCN - Parâmetros Curriculares Nacionais (BRASIL, 1998), abrangendo temas como ética, saúde, meio ambiente, orientação sexual, pluralidade cultural, trabalho e consumo. A pertinência dos assuntos indicados nos PCN é de incontestável relevância, no entanto, este estudo foi realizado com foco no livro didático do ensino fundamental na abordagem de educação em saúde.

Este estudo investigou, especificamente, no livro de sétimo ano do ensino fundamental de maior adesão nas escolas estaduais no município de Boa Vista/RR, a ocorrência de analogias e sua classificação, conforme modelo proposto por Nagen et al (2003) na abordagem da educação em saúde.

\section{Justificativa.}

As escolas estaduais do ensino fundamental de Boa Vista-RR adotam livros didáticos ofertados pelo Ministério da Educação. Mesmo diante da oferta de mais de um autor na escolha do livro didático, todos possuem uniformização dos conteúdos para todo o Brasil, com isso, desconsiderando a relevância do contexto local social, regional e cultural dos educandos.

As analogias podem ser amplamente utilizadas como ferramentas de ensino, porém, o entendimento e domínio do seu uso é objeto de estudo mesmo nos livros didáticos. A analogia quando utilizada inadequadamente, seja por desconhecimento do objeto análogo por parte dos educandos ou pela fragilidade na similaridade entre o análogo e o alvo, resulta em conflitos na identificação e no entendimento do assunto alvo (DUARTE, 2005).

Os Parâmetros Curriculares Nacionais (PCN) trazem no contexto dos temas transversais as exigências da abordagem de educação em saúde e, principalmente em ciências, aproximando os conteúdos obrigatórios trabalhados no Ensino Fundamental. A 
relevância da abordagem de educação em saúde neste período escolar não foi o foco deste trabalho, mas está fortemente argumentado nos PCN e na mídia nacional.

Com o entendimento da fundamental importância da educação em saúde nas escolas e sabendo que estas utilizam os livros didáticos em suas atividades docentes, cujos temas não são elaborados conforme o contexto da realidade de cada região formulou-se assim a justificativa deste trabalho investigativo, quanto ao uso de analogias na abordagem de educação em saúde nos livros didáticos do sétimo ano.

\section{Fundamentação Teórica.}

Analogia é um termo amplo e de apropriação de mais de uma linguagem da área do saber. Diversos autores elaboram diferentes conceitos e definições para melhor elucidar e se apropriar do termo nos seus trabalhos. Como por exemplo, Haaparanta (apud HOFFMAN \& SCHEID, 2007, p. 4) definiu analogia "como um conceito matemático que significava proporção". Glynn et al (2007) afirmam que analogia "é uma comparação das semelhanças dos dois conceitos. O conceito familiar é chamado de analógico e do desconhecido a um alvo". Nagen et al (2003) definem analogia como sendo "o sentido de extensão provável do conhecimento mediante o uso de semelhanças genéricas que se podem estabelecer entre situações diversas”.

As diferentes maneiras do emprego das palavras são peculiares da linguagem de cada autor. Porém, ocorre o entendimento comum que analogia é uma forma de estabelecer comparações e ou relações entre duas "coisas" distintas. Este entendimento é parcialmente compartilhado em Biologia onde os análogos são de origens diferentes, mas com a mesma função.

Em síntese, analogia é definida no dicionário português por Ferreira (2006) como "1. ponto de semelhança entre duas coisas diferentes. 2. Semelhança (2). 3. Gram. Modificação ou criação de uma forma lingüística por influência de outra(s) já existente(s)".

O uso das analogias é facilmente incorporado na linguagem coloquial no discurso didático, levando à utilização indiscriminada das analogias. Conforme Hoffmann e Scheid (2007) "professores e autores de livros didáticos, assim como todos os seres humanos, são predispostos a pensar analogicamente e, conseqüentemente, utilizam analogias em suas explicações. Nesta facilidade para explicar através de termos fáceis e comuns, ocorre a possibilidade de generalizações, banalizando e simplificando o "complexo" ao ponto do educando não conseguir alcançar o novo conhecimento, 
ficando limitado em explicar o "mundo" a partir de um conceito simplista e pouco fundamentado, distanciando-se do científico. Contexto este defendido por Bachelard (1996) no livro Formação do Espírito Científico, onde as generalizações são os “obstáculos epistemológicos". Em análise aos conceitos de Bachelard, Costa apud Gomes e Oliveira (2007) enfatizam que a generalização

[...] facilita momentaneamente uma compreensão, mas esse entendimento
pode bloquear o interesse pelo estudo mais aprofundado. A lei geral é
suficientemente satisfatória para que se perca o interesse por estudá-la. Parte
dos obstáculos propostos é, de alguma forma, consequiência de
generalizações inapropriadas, de modo que o conhecimento geral acaba
sendo um conhecimento vago.

As críticas sobre as analogias feitas por Bachelard não se concentram no mérito do método, mas nas possibilidades do uso inadequado por educadores desprovidos de recursos didáticos pedagógicos e cognitivos. As dificuldades da utilização eficiente e eficaz das analogias podem estar sendo influenciadas por algumas falhas no processo de ensino e aprendizagem, dentre elas, Duarte (2005) aponta quatro razões:

- A analogia pode ser interpretada como o conceito em estudo, ou dela serem
apenas retidos os detalhes mais evidentes e apelativos, sem se chegar a
atingir o que se pretendia;
- Pode não ocorrer um raciocínio analógico que leve à compreensão da
analogia;
- A analogia pode não ser reconhecida como tal, não ficando explícita a sua
utilidade;
- Os alunos podem centrar-se nos aspectos positivos da analogia e
desvalorizar as suas limitações.

Apesar das recomendações de quanto aos riscos do uso das analogias, elas compõem importante ferramenta nas estratégias de ensino, sendo utilizadas por professores e autores dos livros didáticos, gerando objeto de estudos para muitos pesquisadores. Duarte afirma que as principais investigações nos livros didáticos estão centradas nos "objetivos, metodologia de análise, níveis de escolaridade investigados, áreas disciplinares mais contempladas e principais resultados”.

O modelo de ensino centrado nas analogias pode ter três enfoques: centrado no professor, centrado no aluno ou centrado no professor e aluno. Aquelas centradas no professor são definidas por Glynn et al (2007), Nagem et al (2003), e outros.

O modelo centrado no aluno apresentado por Wong apud Duarte (2005) compreende um conjunto de quatro fases: “(1) explicação do fenômeno em estudo; (2) concepção de analogias que permitam compreender o fenômeno; (3) aplicação da analogia ao fenômeno, apontando as semelhanças e diferenças; (4) avaliação da adequação das analogias propostas”. 
As estratégias de analogias centradas no aluno e professor, estão melhor argumentadas por Cachapuz (1989). Os autores também propõem sistematizações para caracterizar o tipo de analogia utilizada no livro, pelo professor e ou alunos. Ferraz \& Terrazzan (2011), classificam o uso das analogias, quanto ao nível de organização, através de um conjunto de nove categorias.

O modelo utilizado como método para classificar as analogias neste estudo é o proposto por Nagen (2003) e compreende seis tipos de analogias:

Estrutural: quando o objeto analógico pode ser comparado com o objeto real na sua forma.

Funcional: quando o objeto analógico pode ser comparado ao objeto real no seu funcionamento.

Conceitual ou congelada: quando os termos já são utilizados há anos, não trazendo nenhuma surpresa ao leitor (congelada) ou quando os termos definem o fenômeno, ou seja, é considerado sinônimo.

Antrópica: quando a frase transmite uma idéia de racionalidade, egocentrismo, atribuindo aos objetos ou fenômenos característicos dos seres humanos.

Zootrópica: quando a frase transmite uma idéia de morfologia ou comportamento, atribuindo aos animais.

Fitotrópica: quando a frase transmite uma idéia de morfologia ou comportamento, atribuído aos vegetais.

As tentativas de integrar ao ensino escolar conteúdos de educação em saúde vêm ocorrendo desde o século passado, sendo representadas por disciplinas como: "Higiene, Puericultura, Nutrição e Dietética ou Educação Física, e, mais recentemente, Ciências Naturais e Biologia" (BRASIL, 1998). Estas investidas resultaram em conceitos comuns dos mecanismos de saúde e doença, sem contextualizar a relação de saúde e doença aos hábitos de higiene, profilaxia, pertinências culturais e ambientais. Em 1971, ficam estabelecidos na Lei $\mathrm{n}^{\text {o }}$ 5.692, os programas de saúde nas escolas. Em 1977, novas reformulações na educação ocorreram por conta do Conselho Federal de Educação (MANHÃES, 1996).

Em Boa Vista/RR, localizada no extremo norte da Amazônia Legal, as doenças tropicais e as oportunistas por conta dos problemas de saneamento básico merecem especial atenção dos programas de educação em saúde; neste contexto a educação em saúde nas escolas é ponto fundamental no processo educacional para redução dos problemas regionais.

A conferência Nacional de Saúde on-line do Ministério da Saúde, dirigida por Sylvain Nahum Levy, entende que educação "só pode ser verdadeiramente compreendida e analisada sob enfoques que definem o próprio ser humano; em particular o biopsicológico e o sociológico". Do ponto de vista biopsicológico a 
educação tem por objetivo "levar o indivíduo a realizar suas possibilidades intrínsecas, com vistas a formação e ao desenvolvimento de sua personalidade". E na visão sociológica a educação "é um processo que tem por fim conservar e transmitir cultura, atuando como importante instrumento e técnica social".

Já, as definições de saúde são diversificadas e complexas sendo entendidas conforme o ponto de vista que cada um tem sobre o que é ter saúde e ou ser saudável. Na busca de um conceito dinâmico de saúde os PCN (BRASIL, 1998), resumem que saúde é, portanto, produto e parte do estilo de vida e das condições de existência, sendo a vivência do processo saúde/doença uma forma de representação da inserção humana no mundo.

A Organização Mundial de Saúde (OMS) define saúde como um "estado de completo bem-estar físico, mental e social, e não meramente a ausência de doenças" (TAYLOR et al, 2007). Considerando que a definição de saúde da OMS é atualmente a definição mais aceita. Conclui-se que saúde é um contexto de bem estar em um processo contínuo na melhor qualidade de vida física e mental no meio onde o homem vive. Segundo a OMS, os objetivos da educação em saúde são "de desenvolver nas pessoas o senso de responsabilidade pela sua própria saúde e pela saúde da comunidade a qual pertençam e a capacidade de participar da vida comunitária de uma maneira construtiva".

Educação em saúde adquire proporções maiores que a definição de educação e de saúde, sendo entendida e definida em um processo complexo e, quando superficialmente interpretada, pode romper a fronteira de suas ações com as de educação ambiental; uma vez que todas as ações do ser humano convergem diretamente ou indiretamente a sua própria saúde, no sentido amplo do termo.

\section{Metodologia}

Como metodologia de trabalho foi realizada uma pesquisa do tipo documental analítica, fundamentada no método dedutivo comparativo. Como instrumento de coleta de dados utilizou-se a observação não participante de Richardson (2009), em que o investigador não toma parte nos conhecimentos do estudo, apenas atua como espectador atento.

A partir da observação de $15 \mathrm{~h} /$ aula de cinco diferentes docentes do $7^{\circ}$ ano, foram gerados os dados qualitativos que aparecem ao longo da análise. 
Os dados quantitativos das escolas estaduais em Boa Vista/RR foram relacionados segundo o Censo de Janeiro de 2009, da relação de gestores, administradores e coordenadores pedagógicos fornecido pelo Departamento de Educação Básica do Estado de Roraima.

Para a seleção dos livros didáticos de quinto a oitavo anos foi levado em consideração o livro mais solicitado em cada ano nos pedidos das escolas envolvidas e registradas no Site do FNDE (BRASIL, 2009).

Os assuntos de educação em saúde abordados no livro foram interpretados e analisados através de leitura sumária. Utilizou-se como referencial o que se entende por educação em saúde, segundo a OMS e a busca de classificar as analogias nos textos, teve como elemento norteador o modelo de classificação proposto por Nagen et al (2009), gerando as discussões e considerações desta parte do estudo.

\section{Análise do estudo}

O Censo de janeiro de 2009, da relação de gestores, administradores e coordenadores pedagógicos fornecido pelo Departamento de Educação Básica, contém a relação de todas as escolas estaduais com sede em Boa Vista/RR, registrando no total, 61 escolas. Destas, 30 são de ensino do $1^{\circ}$ a $8^{\circ}$ anos; 11 têm de $1^{\circ}$ a $4^{\circ}$ anos; 10 de $5^{\circ}$ a $8^{\circ}$ anos; 06 de ensino médio; 02 de $6^{\circ}$ a $8^{\circ}$ anos; 01 com Educação para Jovens e Adultos (EJA) e 01 de $2^{\circ}$ a $8^{\circ}$ anos. Foram selecionadas todas as 30 escolas de $1^{\circ}$ a $8^{\circ}$ ano do ensino fundamental independente de possuírem no programa o ensino médio e ou EJA.

Segundo o site do Fundo Nacional de Desenvolvimento da Educação (BRASIL, 2009), 28 escolas receberam os livros de $5^{\circ}$ a $8^{\circ}$ anos, uma não solicitou livros e outra não fez pedido apenas para oitavo ano.

Neste estudo, a amostra analisada foi a do livro didático mais utilizado no $7^{\circ}$ ano do Ensino Fundamental das escolas estaduais em Boa Vista/RR, conforme demonstrado no quadro 1 . Os comentários utilizados como dados qualitativos tiveram sua origem na observação de 15h/aula de pratica docente envolvendo cinco professores de ciências do $7^{\circ}$ ano, quando trabalharam a temática educação em saúde com os alunos. A amostra foi selecionada devido à pertinência dos conteúdos do sétimo ano, o corpo humano, com o vasto campo de abordagem na educação em saúde na prática docente e no livro didático. 
Ensino, Saúde e Ambiente - V6 (3), pp. 129-141, dez. 2013

Quadro 1: Livros didáticos de ciências do sétimo ano utilizados nas escolas estaduais de ensino fundamental, de $1^{\circ}$ a $8^{\circ}$ anos no município de Boa Vista.

\begin{tabular}{|c|c|c|c|}
\hline ANO & $\begin{array}{c}\text { TÍTULO DOS LIVROS ESCOLHIDOS PELAS } \\
\text { ESCOLAS DE } 1^{\circ} \text { A } 8^{\circ} \text { ANOS }\end{array}$ & AUTOR & $\begin{array}{l}\mathrm{N}^{\circ} \text { DE ESCOLAS } \\
\text { SOLICITANTES }\end{array}$ \\
\hline \multirow{4}{*}{$7^{\circ}$} & Ciências: NOSSO CORPO & Gewandsznajder, F. & 8 \\
\hline & CIÊNCIAS NATURAIS & Fonseca, A. et al & 1 \\
\hline & CONSTRUINDO CONSCIÊNCIAS - CIÊNCIAS & Braga, S.A.M. et al & 7 \\
\hline & O CORPO HUMANO & Barros \& Paulino & 13 \\
\hline
\end{tabular}

O livro selecionado para o sétimo ano - O Corpo Humano (BARROS \& PAULINO, 2006) é composto por cinco unidades: Unidade I: A organização do Corpo Humano, (capítulos 1-4). Unidade II: A Reprodução, (capítulos 5-8). Unidade III: As Funções de Nutrição, (capítulos 9-14). Unidade IV: Funções de Relação com o Ambiente, (capítulos 15 e 16) e Unidade V: A coordenação das Funções Orgânicas, (capítulos 17 e 18) e um capítulo extra: Conservação da saúde.

\section{Unidade I: A Organização do Corpo Humano (capítulos 1-4).}

No capítulo 1, o texto "O ser Humano: um animal social" (p.8-13) sugere trabalhar em grupo sobre a inclusão social dos portadores de necessidades especiais. $\mathrm{O}$ texto afirma que as "Crianças deficientes físicas ou mentais podem se desenvolver como quaisquer outras e ser pessoas alegres, autoconfiantes, com boas respostas a estímulos e ensinamentos, desde que sejam aceitas e incluídas na sociedade".

Após o capítulo 1, somente no capítulo 4 "Níveis de organização do corpo humano" (p.28-40), o autor retoma questões de educação em saúde. Em cada assunto deste capítulo há um texto de educação em saúde; alguns são recortes de reportagens de revistas e jornais, outros são próprios do autor. Mas nenhuma destas matérias traz no seu discurso o uso de analogias. São utilizados termos científicos, porém com linguagem acessível e direta.

\section{Unidade II: A Reprodução (capítulos 5-8).}

A educação sexual exaustivamente denunciada como tabu é um problema social que se estende da casa a escola. Esta unidade é composta por quatro capítulos, do quinto ao oitavo. O fato de este tema estar no início do livro didático força o professor a trabalhar educação sexual no primeiro semestre do ano letivo.

Dos quatro capítulos da Unidade II, três destes trabalham o tema transversal de educação sexual. Nestes capítulos são abordados: a menarca (primeira menstruação), produção de esperma, fertilidade, namoro, sexo, doenças sexualmente transmissíveis, higiene íntima masculina, fimose, tipos de métodos contraceptivos e preservativos 
utilizados pelo homem e mulher, gravidez e gravidez indesejada, pré-natal, amamentação, problemas sociais decorrente do sexo não seguro e orientação para consultar com um profissional de saúde quando desejar iniciar vida sexual.

O capítulo 5: "O Sistema Genital” (p.42). Inicia um texto com o título "Falando de Sexo": "Em outros tempos, sexo era muitas vezes um assunto proibido. Em casa, ninguém falava "dessas coisas" (p. 43). No decorrer do texto o autor pergunta ao leitor para que serve o sexo? E logo abaixo vem a resposta de forma genérica para os animais e no segundo parágrafo está a pergunta para os seres humanos. A resposta é:

Para os seres humanos, geralmente a reprodução é apenas uma das funções da atividade sexual. A relação sexual é também uma maneira de obter prazer e alegria, de dar e receber carinho, afeto. É uma das expressões mais íntimas que pode haver no relacionamento entre duas pessoas, pois envolve emoções profundas. Não é à toa que a relação sexual também é chamada de "fazer amor".[...] (BARROS \& PAULINO, 2006).

Os assuntos sobre sexo e sexualidade são abordados de forma clara e objetiva estando em consonância com as determinações dos PCNs e com o Ministério da Saúde. $\mathrm{Na}$ publicação do manual técnico de assistência em planejamento familiar, pelo Ministério da saúde, dispõe um capítulo para tratar exclusivamente da anticoncepção na adolescência porque,

O elevado número de partos entre as adolescentes, o início cada vez mais precoce das relações sexuais e o aumento das DST/AIDS nessa faixa etária, justificam a atenção de uma assistência adequada às necessidades da população na faixa etária de 10 a 19 anos (BRASIL, 2007).

\section{Unidade III: As Funções de Nutrição (capítulos 9-14).}

Nesta unidade, é abordada a importância dos alimentos, a alimentação saudável, a digestão a respiração a circulação e a excreção. A educação em saúde é apresentada na prevenção de doenças causadas por falta da ingesta de frutas, legumes e verduras. Também questões de hidratação, uso dos óleos de cozinha e os riscos com o colesterol bem como os hábitos saudáveis de saúde para evitar as doenças. E ainda, como proceder aos cuidados em lavar os alimentos e as mãos. Já para os produtos industrializados, é preconizado observar o prazo de validade, ferrugem, amassado nas latas etc.

No capítulo 11 "A Digestão" (p.114). Os temas transversais de educação em saúde estão no controle de peso através da alimentação saudável e equilibrada, higiene bucal, incluindo reportagens da revista Veja e relatórios do site do Ministério da Saúde.

O capítulo 12: “A respiração" (p.129). São trabalhadas as doenças provocadas pelo uso do fumo e a tuberculose, com reportagem de jornais sobre esta doença. Nos capítulos 13 e 14 são trabalhados os demais sistemas do corpo humano e os cuidados 
que devemos ter com a saúde, bem como os hábitos de uma vida mais saudável, incluindo as imunizações através de vacinas. Ao término desta unidade observou-se a inexistência do uso das analogias.

\section{Unidade IV: Funções de Relação com o Ambiente (capítulos 15-16).}

Os dois capítulos desta unidade tratam respectivamente da locomoção e dos sentidos. O capítulo sobre locomoção (capítulo 15) apresenta como tema transversal os cuidados com o esqueleto e articulações orientando como prevenir os problemas de postura, como por exemplo:

- $\quad$ Mantenha sempre uma postura correta - ao andar, sentar-se ou ficar em pé. Ao sentar, mantenha toda a extensão das costas apoiada na cadeira ou no sofá

- $\quad$ Evite carregar muito peso ou transportar objetos pesados apenas de um lado do corpo. Isso vale para quando você estiver levando, por exemplo, sua mochila cheia de cadernos e livros![..] (BARROS \& PAULINO, 2006).

O segundo capítulo desta unidade, “Os Sentidos” (capítulo 16, p.187), os conteúdos são: tato, gustação, olfato, audição, visão e a fonação. Os Temas transversais de educação em saúde são explanados no estudo de cada um dos sentidos. Na página 193, o autor descreve algumas recomendações quanto ao uso do cotonetes, afirmando que ele

[...] pode servir para limpar a parte visível da orelha. Ele tem uma haste plástica e flexível, com as pontas cobertas de algodão.

Nas caixas de cotonetes há um alerta para que as pessoas não introduzam a haste do cotonete no canal da orelha, pois isso pode causar danos, caso em que se deve procurar assistência médica (BARROS \& PAULINO, 2006)..

Também existem recomendações de saúde específicas para pele, visão e fonação. Porém nenhum dos textos utiliza analogia como recurso didático.

\section{Unidade V: A Coordenação das Funções Orgânicas (capítulos 17-18).}

Composta por 2 capítulos: o primeiro trata do sistema nervoso central e periférico (capítulo 17), e o segundo, o sistema endócrino (capítulo 18).

Nas páginas iniciais do primeiro capítulo desta unidade, o autor trabalha a anatomia e fisiologia do sistema nervoso central e periférico humano. Dando seqüência ao assunto o autor discute o que é uma mente sadia. Depois sugere "Desafios do Presente", trazendo textos polemizando o uso das drogas licitas e ilícitas e os efeitos sobre o sistema nervoso e os prejuízos na vida social do usuário de drogas (p. 212-116).

O último capítulo "O Sistema Endócrino", é introduzido como tema transversal de educação em saúde, os perigos do uso dos esteróides anabolizantes. Com um texto da revista “Época, n.327, 23/8/2004, p.68-70” (p.220-221) 


\section{Capítulo extra: Conservação da Saúde}

Nas últimas páginas do livro (p. 225-229). Este capítulo Aborda as orientações de consciência ecológica e prevenção de acidentes com eletricidade, fogões de cozinha, panelas e facas. Ingestão de remédios e manipulação de produtos tóxicos ou inflamáveis e acidentes provocados por quedas no solo em geral. O capítulo é finalizado com primeiros socorros nos pequenos acidentes domésticos (p. 230-231). Mesmo com forte tendência em restringir a abordagem ao processo saúde e doença que segundo os PCNs, as experiências

\footnotetext{
"mostram que transmitir informações a respeito do funcionamento do corpo e das características das doenças, bem como de um elenco de hábitos de higiene, não são suficientes para que os alunos desenvolvam atitudes de vida saudável" (BRASIL, 1998).
}

$\mathrm{O}$ autor proporcionou oportunidades para reflexões e atividades em aula diversificando as fontes de informações. Contudo fica registrada a inexistência de analogias como recurso didático nos temas transversais de educação em saúde.

\section{Considerações Finais}

A abordagem de temas transversais de educação em saúde, ainda é um grande desafio tanto no livro didático quanto na sala de aula, principalmente na tentativa de alcançar os objetivos propostos pelo Ministério da Educação.

Ao direcionar o foco do estudo, no uso de analogias, ficou evidente que o autor do livro didático de ciências do sétimo ano do ensino fundamental, selecionado pela maioria das escolas estadual em Boa Vista/RR, não utilizou analogias na abordagem dos temas transversais de educação em saúde. Entretanto, estes resultados obtidos não podem ser considerados uma mudança no modelo de abordagem dos temas transversais de educação em saúde do livro didático, pois nas observações realizadas envolvendo a prática docente, os cinco professores observados utilizaram analogias para facilitar a compreensão dos alunos.

O estudo evidenciou também a impossibilidade de se estabelecerem inadvertidamente conceitos reducionistas generalizando o uso das analogias, pois a contribuição do livro didático em sala de aula na perspectiva do professor que trabalha com temas transversais, retoma os anseios de novas investigações na busca de aprofundar os conhecimentos nesta área. Em se tratando de um trabalho exploratório, pretendemos retomar a proposta na continuidade deste tema, para conhecermos melhor o perfil dos professores envolvidos, pois constatamos que a analogia é utilizada por eles, 
como ferramenta valiosa entre conhecimentos diferentes, um conhecido e outro desconhecido, sendo muito importante na aprendizagem de conceitos difíceis.

\section{REFERÊNCIAS}

BACHELARD, G.A.A. Formação do Espírito Científico: Contribuição para uma Psicanálise do Conhecimento. Trad. Estela dos Santos Abreu. Rio de Janeiro: Contraponto, 1996.

BARROS, C., PAULINO, W.R - Ciências - O Corpo Humano $7^{a}$ série. Ed. Reform. São Paulo: Ática, 2006.

BRASIL. Secretaria de Educação Fundamental. Parâmetros Curriculares Nacionais: terceiro e quarto ciclos: apresentação dos temas transversais/ Secretaria de Educação Fundamental. Brasília: MEC/SEF, 1998.

BRASIL.- FNDE. Fundo Nacional de Desenvolvimento da Educação. Disponível em: www.fnde.gov.br/pls/simad_fnde/!simad_fnde.sisadweb_1_pc. Acessado em 01/07/2009.

BRASIL. Ministério da Saúde. Educação Em Saúde Histórico, Conceitos e Propostas. Brasília, 2007 Disponível em: http://www.datasus.gov.br/cns/datasus.htm

CACHAPUZ, A. - Linguagem metafórica e o ensino de ciências. In: Revista Portuguesa de Educação, 2(3), 117-129, 1989.

DUARTE, M.C. Analogias na educação em Ciências: Contributos e desafios. Investigação em Ensino de Ciências, Porto Alegre, v. 10, n. 1, 2005.

FERREIRA. A.B.H. Minidicionário da língua portuguesa. 6 ed. $7^{\mathrm{a}}$ impressão rev.atualiz.Curitiba, 2006.

FERRAZ, D.F.; TERRAZZAN, E.A. - O uso de analogias como recurso didático por professores de Biologia no ensino médio. Abrapec - Associação Brasileira de Pesquisa em Educação em Ciências, São Paulo, v.1, n.3, set/dez 2001 disponível em http://www.fae.ufmg.br/abrapec/revista/index.html

GLYNN, S.M.; LAW, M.; GIBSON, N.; HAWKINS, C. H. Teaching science with analogies: a resource for teachers and texbooks authors, 1998. Disponível em $<$ http://curry.edschool.virginia.edu/go/clic/nrrc/scin_ir7.html. Acesso em: 18 Mar. 2009.

GOMES, H.J.P., OLIVEIRA, O.B. - Obstáculos epistemológicos no ensino de ciências: um estudo sobre suas influências nas concepções de átomo. Ciências \& Cognição; Ano 04, Vol. 12, 2007. Disponível em www.cienciasecogniçao.org Acessado em $15 / 03 / 2009$. 
HOFFMANN, M.B., SCHEID, N.M.J. - Analogias como Ferramenta Didática no Ensino de Biologia. Revista Ensaio, v9, n1, 2007 Disponível em :

http://www.fae.ufmg.br/ensaio/v9 n1/analogias-como-ferramenta-didatica-no-ensinode-biologia-marilisa-hoffmann_neusa-scheid.pdf . Acesso em: 18 Mar. 2009.

MANHÃES, L.C.L. Estrutura e Funcionamento do Ensino: Legislação Básica para $1^{o}$ e $2^{o}$ graus. Florianópolis: UFSC, 1996.

NAGEM, R.L.; FIGUEROA, A.M.S.; SILVA, C.M.G., CARVALHO, E.M. - Analogias e metáforas no cotidiano do professor. CEFET- MG, Belo Horizonte, 2003. Disponível em <http://www.anped.org.br/reunioes/26/outrostextos/mc08ronaldonagem.doc $>$ Acesso em: 18.04.2009.

NAGEN, R.L.; CARVALHAIS, D.O.; DIAS, J.A.Y.T. - Uma proposta de ensino com analogias. Revista Portuguesa de Educação. Braga, v. 14, n. 1, p. 197- 213, 2001.

RICHARDSON, R.J. - Pesquisa Social: métodos e técnicas São Paulo: Atlas, 2009.

TAYLOR, C.; LILLIS C.L.; LEMONE P.; Tradução Regina Machado Garcez, Ana Thorell. Fundamentos de Enfermagem. 5 ed. Porto Alegre: Artmed, 2007. 